PSS PROCEEDINGS

\title{
Hector - colleague and friend for fifty years
}

\section{Myron Bander}

Department of Physics and Astronomy,

University of California, Irvine, California 92697, USA

E-mail: mbander@uci.edu

Quarks, Strings and the Cosmos - Héctor Rubinstein Memorial Symposium

August 09-11, 2010

AlbaNova Stockholm) Sweden 
Hector himself did not trust his mathematical prowess, yet he knew well what mathematics had to be tackled for the solution of some physics problem. If a more mathematically capable collaborator would make a mistake and provide a wrong answer, Hector became unhappy. This intuition served us well in several of the projects we undertook together. Such seemingly contradictory behavior occurred in other contexts. Openly, he was super critical of almost everyone, including his friends, but at the same time he was a good friend. Often, in private, he would express disdain for a colleague and then turn around to help and work with this person. I am sure that I was, at times, the butt of such disdain, but I know for sure that I could count on his friendship..

We first met in 1957 when he arrived at Columbia University in New York to begin graduate work; I was finishing my undergraduate studies and soon also started my graduate program. When he arrived he did not, initially, make a strong impression on fellow students. However, in a short time we all realized that that Hector was a personality, with original views and opinions, worth paying attention to. On starting our thesis research, we were provided desks next to each other in a theory student's "bull pen"; we were in daily proximity for about two years. Aside from discussing each others physics problems, we spent a considerable time on other topics; mostly we argued about politics, American, Argentinian, Israeli, etc. With his, then, very ambivalent attitude to Israel and Zionism, I could not have imagined that twenty years later we would be strolling the streets of Jerusalem speaking Hebrew to each other. As with everything, Hector would forcefully express his opinion of United States policies. With his usual uninhibited critique, he would exclaim "..the US is a piece of s..t". This, unfortunately, got him into difficulties later on, when he had trouble obtaining a visa to reenter the US. We spent a lot of time playing the Asian board game "Go" together; this probably delayed the completion of our respective theses by at least six months. Playing is perhaps a misnomer - we would belittle each others abilities, accuse each other of cheating and making up rules. Hector had a very short memory for any game he lost. I am told he showed similar behavior when playing tennis. At times we would meet on Sundays to have lunch and to play go in some Chinatown dim sum restaurant. New York provided many other distraction we enjoyed together such as museums, Lewisohn Stadium with its outdoor concerts as well as other musical events. I finished in 1962 and, despite personal setbacks, Hector finished soon after. Immediately afterwards, both of us went for post-doctoral work in Europe.

We next overlapped in Paris, where Hector arranged for me to spend several months at Orsay as well as securing a room for me at the Cite Universitaire. We started a collaboration, which never came to a conclusion, on the N/D method and trying to bootstrap particle resonances. After this stay in Paris I came back to the United States and soon there after Hector took a permanent position at the Weizmann Institute. In 1968-69, I spent a sabbatical year at the Weizmann, but, unfortunately, Hector was spending the year in New York. We met for a short time at the 1968 Rochester Conference in Vienna; Hector gave me a detailed account of the work he had been doing on finite energy sum rules and what ultimately evolved into the Veneziano Model.

For several years we maintained contact mostly by letter. Every time I would proctor some examination, I would write to him. One time we did meet during this period was during a common visit to CERN, when I finally had a chance to meet his wife Helen.

During the time he was changing jobs and residences from Israel to Sweden, he spent three months as a Visiting Professor with me in Irvine. This was followed by more frequent visits by Hector to Irvine and by me to Stockholm or to Uppsala. Stockholm proved to be a convenient 
stopping point on several trips my wife, Carol, and I made to the Soviet Union. Once, after Hector arranged the details of the journey from Sweden to Leningrad with a stop over at Helsinki University. I gave him the sobriquet 'Tour Zafon', Hebrew for Tour North; this was a play on Tour Darom (Tour South), the name of a travel agency in Rehovot used by the Weizmann Institute. The name Tour Zafon was picked up by the Weizmann physics crowd. Carol and I very much enjoyed summer visits when we would spend time with Helen, Hector, their children, and later grandchildren at their summer house in Ingarö. In physics we had an extensive collaboration studying the properties of strong interactions in the presence of very intense magnetic fields, as those found in astrophysical objects. We were able to obtain support through joint Swedish-US collaborative research funding, which permitted more frequent contacts. Aside from our joint work, Hector used his visits to Irvine to set up a Swedish involvement in several astroparticle endeavors at the South Pole, the AMANDA and Ice Cube collaborations. Although his bluntness often annoyed colleagues, the staff and students looked forward to his visits. Secretaries made efforts to ease bureaucratic hurdles and make sure of timely travel reimbursements. Students found him approachable and encouraging.

Hector was was one of the first particle theorists, at least among my close colleagues, to realize that interest was migrating from traditional particle physics to early universe cosmology. With typical Hectorism and lack of diplomacy he would state: "so they will find the Higgs, so what?", "the SSC, the LHC, a disaster, a scandal!". I am grateful to him, not for deprecating particle physics, but for getting me excited about cosmology. Due to him, I was an enthusiastic supporter of building, what has turned out to be a successful cosmology effort here in Irvine.

Peripheral to physics collaborations, we made two interesting tourist trips. During a joint stay in Israel, we with our wives, profited from the new Israel-Jordan peace agreement to visit the latter. It was an enjoyable, interesting four day excursion. On an other occasion Hector and I "disguised" ourselves, as did Adam Schwimmer, as cosmic ray physicists to attend a conference in Lhasa, Tibet. Carol accompanied us on this journey. To get to Lhasa we made a four day road trip from Kathmandu, Nepal. As in any such exotic trip, there were situations, which at the moment were worrying, but in retrospect are comical.

As his health began to deteriorate, bypasses, heart attacks, Hector made fewer trips to California. We communicated electronically, email and Skype. During stays in the hospital, no matter how serious his condition, he always had his laptop with him. In addition to usual discussions he would bad mouth whatever medical system was treating him. We last saw Hector in the summer of 2006, on our way to a conference in Moscow.

Hector, certainly, left an impact on the particle physics and astrophysics community around the world. Carol noted that where ever in the world we met with a group of physicists, the conversation was bound to get to Hector. In a more facetious manner, I would often remark that if you called a random Physics Department, Hector was there the week prior or was coming the week after. Once, on the day Hector left, after one of his visits to Irvine, I had an occasion to speak by telephone to a mutual colleague, Eliezer Rabinovici. After my comment that "I was recovering from a Hector-visit", Eliezer said "never mind, tomorrow you will miss him". I miss him.

\section{Myron Bander}

University of California, Irvine

February 14, 2011 